Conclusion: Adherence to MTX can affect disease activity during follow-up in Korean patients with RA. Our results provide a rationale for patient education to maintain good drug adherence in RA patients, to control disease activity. Disclosure of Interests: None declared

DOI: 10.1136/annrheumdis-2020-eular.1662

\section{FRI0127 1 SUPPRESSION OF RADIOGRAPHIC PROGRESSION AFTER GRADUAL METHOTREXATE TAPERING IN PATIENTS WITH RHEUMATOID ARTHRITIS PATIENTS MAINTAINING LOW DISEASE ACTIVITY - PROSPECTIVE MULTICENTER STUDY-}

K. Katayama ${ }^{1}$, K. Yujiro ${ }^{2}$, T. Okubo ${ }^{1}$, R. Fukai ${ }^{3}$, T. Sato ${ }^{1}$, M. Yuichi ${ }^{4}$, S. Abe ${ }^{5}$, H. Ito ${ }^{5}{ }^{1}$ Katayama Orthopedic Rheumatology Clinic, Rheumatology, Asahikawa, Japan; ${ }^{2}$ Sapporo Rheumatology and Immunology Clinic, Sapporo, Japan; ${ }^{3}$ Fukai Pharmacy, Asahikawa, Japan; ${ }^{4}$ Asahikawa Medical University, Asahikawa, Jordan; ${ }^{5}$ Asahikawa Medical University, Orthopedic Surgery, Asahikawa, Japan

Background: Many studies have been reported to reduce/discontinue Biologics in the treatment of rheumatoid arthritis (RA). In contrast, study for tapering methotrexate (MTX) has been limited $(1,2)$.

Objectives: We prospectively examined whether bone destruction will progress at 48 weeks after tapering or discontinuing MTX (UMIN000028875).

Methods: The subjects were RA patients who have maintained low disease activity or lower for 24 weeks or more in DAS28-CRP after MTX administration. Patients having PDUS Grade 2 or 3 per site by bilateral hand ultrasonography (26 area) were excluded in this study owing to risk for joint destruction. The joint destruction was evaluated by the joint X-ray evaluation by modified total Sharp scoring (mTSS) at 1 year after the start of tapering MTX. Evaluation of clinical disease activities, severe adverse events, the continuation rate during MTX tapering were also evaluated. According to tapering response, prognostic factor for good response for tapering, joint destruction was determined. Predictors for successful tapering MTX and progression of bone destruction were determined. Statistical analysis was performed by t-test or Wilcoxon rank sum test using SAS .13 .2 software

Results: The subjects were 79 (16 males, 63 females). Age average 60.9 years, disease duration 4 years 4 months, MTX dose $8.43 \mathrm{mg} / \mathrm{w}$, DAS28CRP 1.52, DMARDs (24.3\%), ACPA $192.7 \mathrm{U} / \mathrm{ml}(70.5 \%)$, RF $55.6 \mathrm{lU} / \mathrm{ml}$ $(65.4 \%)$.MTX was tapered from an average of $8.43 \mathrm{mg} / \mathrm{w}$ before study to $5.46 \mathrm{mg} / \mathrm{w}$ one year later. In the treatment evaluation, DAS28-CRP increased from 1.52 to 1.84 . $89.7 \%$ of subjects did not progress joint damage. Other disease activities significantly increased (Table 1). The one-year continuation rate was $78.2 \%$. Since tapering effects were varied widely, we divided patients into three groups; Flared group ( $\mathrm{N}=14$, initial MTX dose $8.71 \mathrm{mg} / \mathrm{w}$, final MTX dose $8.42 \mathrm{mg} / \mathrm{w})$, Low response group ( $\mathrm{N}=31$, final $\mathrm{MTX}$ reduction rate $<50 \%$, initial MTX dose $8.93 \mathrm{mg} / \mathrm{w}$, final MTX dose $6.22 \mathrm{mg} / \mathrm{w}$ ), High response group $(\mathrm{N}=34$, final MTX reduction rate $\geq 50 \%$, initial MTX dose $8.5 \mathrm{mg} / \mathrm{w}$, final MTX dose $3.15 \mathrm{mg} / \mathrm{w}$ )(Table 2). Higher RF value at baseline and higher MTX dose at $3 \mathrm{M}, 6 \mathrm{M}$ were predictors of whether a subject was in Low response group or High Response group. Higher RF value and MTSS at baseline and higher MTX dose at $6 \mathrm{M}$ were predictors whether a subject was in Flared group or High response group. Lower age was predictor of whether a subject was in Flared group or Low responder group. Finally, mean $\Delta \mathrm{mTSS} / \mathrm{y}$ in Flared group (0.36) was not significantly higher than in low response group (0.07) and in high response group (0.01).

Table 1

\begin{tabular}{|c|c|c|c|}
\hline & OM & $12 \mathrm{M}$ & $\mathrm{P}$ \\
\hline RF & $47.7 \pm 70.1$ & $59.1 \pm 72.5$ & $\mathrm{NS}$ \\
\hline CRP & $0.15 \pm 0.18$ & $0.30 \pm 0.73$ & $\mathrm{NS}$ \\
\hline ESR & $18.60 \pm 14.28$ & $21.47 \pm 18.08$ & $\mathrm{NS}$ \\
\hline DAS28-E & $2.1 \pm 0.65$ & $2.46 \pm 0.84$ & $0.002^{*}$ \\
\hline DAS28-C & $1.53 \pm 0.34$ & $1.83 \pm 0.70$ & $0.001^{*}$ \\
\hline CDAI & $2.03 \pm 1.78$ & $3.77 \pm 4.08$ & $0.0002^{*}$ \\
\hline SDAI & $2.20 \pm 1.79$ & $3.86 \pm 3.67$ & $<.0001^{*}$ \\
\hline SJC & $0.55 \pm 0.73$ & $1.01 \pm 1.26$ & $0.0041^{*}$ \\
\hline TJC & $0.10 \pm 0.34$ & $0.38 \pm 1.96$ & $0.0128^{*}$ \\
\hline MMP3 & $52.70 \pm 30.14$ & $58.75 \pm 43.20$ & NS \\
\hline HAQ-DI & $0.14 \pm 0.35$ & $0.22 \pm 0.42$ & $0.0165^{*}$ \\
\hline
\end{tabular}

* significant: Pairs test, Average(SD)
Table 2. Predictors for successful tapering MTX and progression of bone destruction

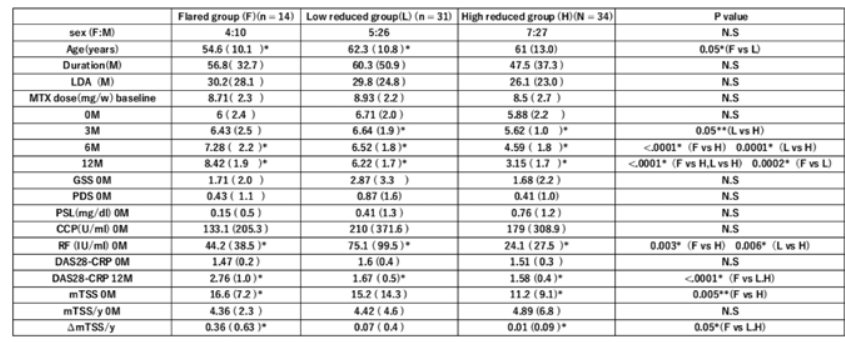

$*_{\text {t-test }}{ }^{* *}$ Willcoxon rank sum test

Conclusion: Patients with MTX-administered low disease activity and finger joint echo PDUS grade 1 satisfy almost no joint destruction even after MTX reduction. For tapering, predictors may be helpful for maintaining patient's satisfaction. References:

[1] Baker KF, Skelton AJ, Lendrem DW et al. Predicting drug-free remission in rheumatoid arthritis: A prospective interventional cohort study. J. Autoimmunity. 2019;105: 102298.

[2] Lillegraven S, Sundlisater N, Aga A et al. Tapering of Conventional Synthetic Disease Modifying Anti-Rheumatic Drugs in Rheumatoid Arthritis Patients in Sustained Remission: Results from a Randomized Controlled Trial. American College of Rheumatology. 2019; Abstract L08.

Disclosure of Interests: None declared

DOI: 10.1136/annrheumdis-2020-eular.1415

\begin{tabular}{|l|l}
\hline FRI0128 & FILGOTINIB PROVIDED RAPID AND SUSTAINED \\
IMPROVEMENTS IN FUNCTIONAL STATUS, PAIN, \\
HEALTH-RELATED QUALITY OF LIFE, AND FATIGUE \\
IN PATIENTS WITH RHEUMATOID ARTHRITIS AND \\
INADEQUATE RESPONSE TO METHOTREXATE: \\
RESULTS FROM THE FINCH 1 STUDY
\end{tabular}

A. Kivitz ${ }^{1}$, Y. Tanaka ${ }^{2}$, S. Lee ${ }^{3}$, L. Ye ${ }^{3}$, H. Hu ${ }^{3}$, R. Besuyen ${ }^{4}$, B. Combe $e^{5,6}$. ${ }^{1}$ Altoona Center for Clinical Research, Duncansville, PA, United States of America; ${ }^{2}$ Univ of Occupational and Environmental Health, Kitakyushu, Japan; ${ }^{3}$ Gilead Sciences, Inc., Foster City, United States of America; ${ }^{4}$ Galapagos BV, Leiden, Netherlands; ${ }^{5}$ Univ Montpellier, Montpellier, France; ${ }^{6}$ UMR 5335 , Montpellier, France

Background: In the FINCH 1 study, filgotinib (FIL)—an oral, potent, selective Janus kinase 1 inhibitor-in combination with methotrexate (MTX) provided significant improvements in the signs and symptoms of rheumatoid arthritis (RA) in patients (pts) with inadequate response to MTX. ${ }^{1}$ While EULAR guidelines recommend a treat-to-target approach focusing on reducing inflammation to prevent joint damage, physical disability, and mortality, pts consider control of pain and fatigue, along with maintenance of physical function and health-related quality of life (HRQoL), to be important aspects for their care. ${ }^{2,3}$

Objectives: To evaluate the rate and magnitude of change in patient-reported outcomes (PROs) from FINCH 1.

Methods: In the FINCH 1 study (NCT02889796), pts with active RA received oral FIL $200 \mathrm{mg}+$ MTX, FIL $100 \mathrm{mg}+$ MTX, PBO + MTX, or subcutaneous adalimumab (ADA) $40 \mathrm{mg}+\mathrm{MTX}$ for up to 52 weeks (W); pts receiving $\mathrm{PBO}$ a W24 were rerandomised 1:1 to FIL 100 or $200 \mathrm{mg}$. PROs included the HAQ-DI and VAS pain scale, SF-36, and FACIT-Fatigue questionnaire. The change from baseline (CFB) at each time point was assessed up to W52 for each treatment group. The mixed-effects model for repeated measures was used to compare each FIL group with PBO for the CFB at each time point through W24. The logistic regression model was used to compare each FIL group with $\mathrm{PBO}$ for the proportion of pts achieving the minimum clinically important difference (MCID) of $\geq 0.22$ reduction in CFB in $\mathrm{HAQ}$-DI at each time point through W24

Results: Of 1755 pts randomised and treated (475 FIL $200 \mathrm{mg}+$ MTX; 480 FIL $100 \mathrm{mg}+$ MTX; 325 ADA + MTX; and 475 PBO + MTX), $1417(80.7 \%)$ received study drug through W52. As early as W2 through W24, pts receiving either dose of FIL experienced nominally significantly greater $(p<0.001)$ CFB in HAQ-DI and VAS pain scale than those receiving PBO; CFB improvements were maintained through W52 (Fig 1A, B). At W2, compared with PBO (40.2\%), a nominally significantly greater proportion of pts achieved the HAQ-DI MCID in both the FIL $200(52.5 \% ; p<0.001)$ and $100 \mathrm{mg}(46.7 \% ; p=0.043)$ groups. This benefit vs PBO was maintained up to W24 and the proportion of pts who achieved a HAQ-DI reduction of $\geq 0.22$ remained $\geq 75.8 \%$ in the FIL $200 \mathrm{mg}$ group and $\geq 71.5 \%$ in the FIL $100 \mathrm{mg}$ group from W12 through W52. FIL provided nominally significantly greater improvement in $\mathrm{HRQOL}$ vs $\mathrm{PBO}$ at W4 